\title{
CRYSTALLIZATION KINETICS OF EVAPORATION RUBIDIUM CHLORIDE IN THE MSMPR CRYSTALLIZER
}

\author{
Kun ZHOU, Jia XIE, Kai YIN, Yue-Yong YAN and Ke WANG \\ College of Materials and Chemistry \& Chemical Engineering, Chengdu University of Technology, Chengdu 610059, China
}

Received May 25, 2018

In the MSMPR crystallizer, the evaporating crystallization kinetics of rubidium chloride was studied. Based on the theory of population balance and experimental population density data of rubidium chloride, the crystallization process of rubidium chloride obey $\Delta \mathrm{L}$ law, and the nucleation and growth rate equations of rubidium chloride were obtained. Theoretical analysis of the kinetic equations show that lower magma density, appropriate temperature and supersaturation are three key factors to get rubidium chloride with bigger mean particle size.

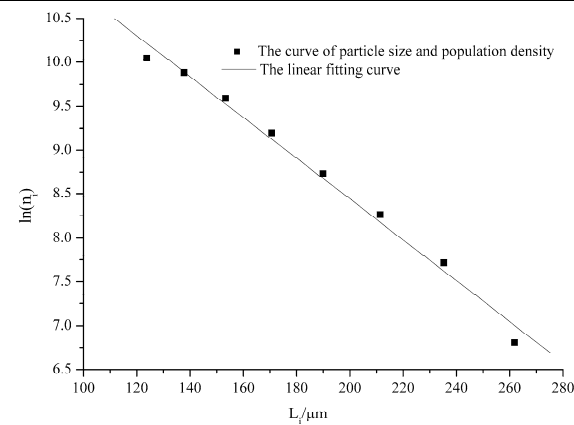

\section{INTRODUCTION}

As an important rare and precious metals resource, rubidium was discovered by German chemists Bunsen R. W. and Kirchhoff G. R. in the analysis of flame spectroscopy in $1861 .{ }^{1}$ With the rapid development of domestic and overseas aerospace industry, nuclear industry, bioengineering, energy industry and other high-tech industries in recent years, rubidium and its compounds with its unique characteristics, its application study received extensive attention, increasingly shows a high commercial value. ${ }^{2-4}$ In medicine rubidium chloride and several other rubidium salts can be used as mass density gradient in DNA and RNA ultracentrifugation separation process, ${ }^{5-6}$ and rubidium chloride also can be widely used as catalyst and biochemical reagents, because rubidium play a very good catalytic effect in the formation of carbon and carbon bond, carbon and nitrogen bond, carbon and oxygen bond these three reactions. Yasunori Ino et al. ${ }^{7}$ had used a rubidium compound $\mathrm{RbH}\left(\eta^{1}-\mathrm{BH}_{4}\right)(\mathrm{dppp})(\mathrm{dpen})$ to catalytic hydrogenation of $\alpha$ or $\beta$-substituted chiral esters without loss of optical purity under mild neutral environment. This method can avoid the quenching step and the extraction step. Another important physical property of rubidium is the photoelectric effect. For example, rubidium silver iodide $\left(\mathrm{RbAg}_{4} \mathrm{I}_{5}\right)^{8}$ is a good electronic conductor, and can be used as an electrolyte of the solid battery, like thin film battery.

Generally, pegmatite and pollucite are mainly solid deposits for rubidium; rich salt lake brine and underground brine are mainly liquid ore for rubidium, but in recent years, ${ }^{9}$ the rubidium concentrate production can not meet domestic consumption, still need to import large quantities of rubidium concentrate from abroad. The salt lake brine reserves in large, wherein rubidium exist mainly in the form of rubidium chloride. The main problem currently facing is how to crystallize larger particle size and uniform rubidium chloride crystals from rich liquid rubidium. According to

*Corresponding author: kunzhou925@163.com 
the physicochemical properties of rubidium chloride, crystallization by evaporation is an effective way to get rubidium chloride crystals. At present, there were no reports on the crystallization kinetics of rubidium chloride. Therefore, this paper measured rubidium chloride evaporation and crystallization kinetics data, including supersaturation, magma density, stirring rate, and established the crystallization kinetics model of evaporation rubidium chloride. The results provide a theoretical basis for the optimization and design of the crystallization process, and the control of crystal size.

\section{EXPERIMENTAL}

\section{Materials}

A white crystalline rubidium chloride powder used to measure the kinetics was purchased from Alfa Aesar (Tianjin) Chemcial Co., Ltd. China. After three times recrystallization from water, its purity was better than $99.5 \%$. The purity of rubidium chloride was determined by inductively coupled plasma optical emission spectrometer (ICP-OES). Ethanol and silver nitrate were prepared in advance.

\section{Apparatus and Procedures}

A schematic diagram of experimental apparatus for rubidium chloride evaporating crystallization can be seen in Figure 1. The main part of the system is a mixed suspension mixed product removal (MSMPR) crystallizer. Its internal diameter was $10 \mathrm{~cm}$ and its height $10 \mathrm{~cm}$. The active volume was fixed at $500 \mathrm{~mL}$. MSMPR crystallizer was designed with a draft tube, and using a diameter of $5 \mathrm{~cm}$ three blade propeller stirrer to ensure that the crystals can be fully mixed in the crystallizer. The temperature of crystal slurry can be kept within $\pm 0.1{ }^{\circ} \mathrm{C}$ by an electric heated water bath. So as to change the rate of evaporation, the crystallizer was worked in a vacuum condition, with the cacuum level controlled by a vacuum pump.

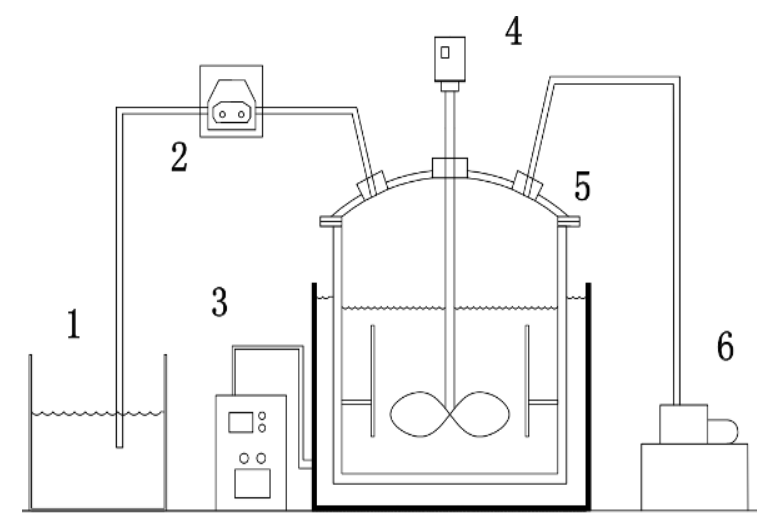

Fig. 1 - Schematic diagram of experimental apparatus for $\mathrm{RbCl}$ evaporating crystallization 1 - feed chute; 2 - peristaltic pump; 3 - electric heated water bath; 4 - stirrer; 5 -MSMPR crystallizer; 6 - vacuum pump.

In a typical experiment, rubidium chloride saturated solution at different tempreature was perpared in advance. After standing for 15 minutes, $500 \mathrm{~mL}$ saturated solution was added to MSMPR crystallizer, which is placed in a constant temperature water bath. When stirring until stable, adjust the degree of vacuum, control the rate of stirring within the crystallizer were $250 \mathrm{rpm}, 350 \mathrm{rpm}$, and $450 \mathrm{rpm}$. By adjusting the evaporation rate and a saturated solution feed rate, to maintain a constant liquid level in the crystallizer. A large number of crystals in solution appears at the beginning of time, sampling every 15 minutes, hot quickly filtered, washed with a saturated ethanol solution rubidium chloride. After using the weighing method called dry weight of the sample was measured particle size distribution.

\section{Sample Analysis}

Rubidium chloride crystals size distribution was measured by the Mastersizer particle size analyzer, using ethanol solution saturated by rubidium chloride as the dispersion phase. The concetration of rubidium chloride in solution was equal to the concentration of chloride ions, which was determined by silver nitrate titration method.

\section{Crystallization Kinetics Model}

One of the main methods of crystallization kinetics is intermittent dynamic method. ${ }^{10,11}$ This method is simple, and a single experiment will be able to get a lot of information from the crystallization process, for the crystallization process of crystal nucleation and growth through different stages. ${ }^{12}$ For the solution crystallization, the theoretical basis of kinetics is the population balance theory. Its general equation formula is ${ }^{13}$ :

$$
\frac{\partial n}{\partial t}+\frac{\partial(G n)}{\partial L}+\frac{Q}{V} n=\frac{Q i}{V} n_{i}+(B-D)
$$

Because of mixed product removal, the residence time of crystals was like with the liquid phase in MSMPR crystallizer. So the crystal growth time (i.e., residence time ${ }^{14}$ ) may be considered equal to the ratio of the effective volume of the mold and the volumetric rate of feed. And the MSMPR crystallizer was operated at steady state with no crystals in the feed stream. Therefore equation (1) can be simplified to ${ }^{15}$ :

$$
\frac{d(G n)}{d L}+\frac{n}{t}=(B-D)
$$

Generating new nuclei in the case of the crystal slurry already exists crystals is called secondary nucleation. ${ }^{16}$ In most crystallization process, the primary nucleation and secondary nucleation is co-existing. Ideally, the primary nucleation produces the first nuclei, and then the secondary nucleation becomes the main source of nuclei. The main mechanism of secondary nucleation is fluid shear stress and contact nucleation. Generally speaking the secondary nucleation is more popular in industrial production. And the secondary nucleation rate can be expressed as the following equations: ${ }^{17}$

$$
B^{0}=K_{n} n_{p}^{h} G^{i} M_{t}^{j}
$$

In the crystal growth process, according to the relationship between the crystal growth rate and crystal size, it is divided into size-irrelated growth and size-related growth. McCabe early proof: when the same kind of crystals was suspended in the supersaturated solution, all geometrically similar crystals are grown at the same rate, i.e. the crystal growth rate has nothing to do with the initial size of the crystal, generally 
referred to as $\Delta \mathrm{L}$ law. ${ }^{15}$ The linear growth rate can be expressed by the following semiempirical equation: ${ }^{18}$

$$
G=K_{g} \exp \left(-\frac{E_{g}}{R T}\right) \Delta C^{g}
$$

\section{RESULTS AND DISCUSSION}

\section{Crystal Size Distributions}

According to the previous theoretical analysis, it need to judge whether the growth process conform to $\Delta \mathrm{L}$ law. Whether there is a linear relationship between population density ${ }^{19}$ and crystal size to distinguish the crystal growth model. A typical experimental population density plot is given in Figure 2. The population density plot exhibits a good linear relationship for crytals sizes between $120 \mu \mathrm{m}$ and $260 \mu \mathrm{m}$, so non-linearity in the crystal size distribution is evident for rubidium chloride evaporative crystallization process.

\section{Crystal Mean Size}

Figure 3 shows a typical SEM photomicrograph of the rubidium chloride crystals produced after typical steady-state MSMPR crystallization. The shape of crystals was more structured, showing cubic. The effect of stirring speed on crystal breakage was investigated on room temperature $\left(25^{\circ} \mathrm{C}\right)$. Crystal slurry was stirred at stirring rate of
$250 \mathrm{rpm}, 350 \mathrm{rpm}$, and $450 \mathrm{rpm}$ for 2 hours. The particle size distribution of the results under the three conditions is shown in Figure 4. Apparent at different stirring speed, the number of primary crystal size and small particle size is not changed significantly. So dynamic model do not consider the impact of crystal breakage, ${ }^{13}$ i.e. $\mathrm{B}=\mathrm{D}=0$.

\section{Effect of Variables on Crystallization Kintics}

The effect of supersaturation and temperature on the crystal growth rate is given in Figure 5, and Figure 6. With the solution had increased supersaturation and temperature, the crystal growth rate has significantly increased, so elevated temperatures help the growth of crystals. When the solution was stirred at different stirring rates on the same temperature, the growth rate of the crystal changes a little. The stirring rate has little effect on the crystal growth rate.

The effect of supersaturation and magma density ${ }^{14}$ on the crystal nucleation rate is shown in Figure 7, and Figure 8. It can be clearly seen from the figure that with the solution had increased supersaturation and magma density, the crystal nucleation rate has increased, but the effect of magma density was more observably than supersaturation. This is because of the increase of magma density, the probability of effective collision between crystal and crystal increases, so the crystal nucleation rate increases along with it.

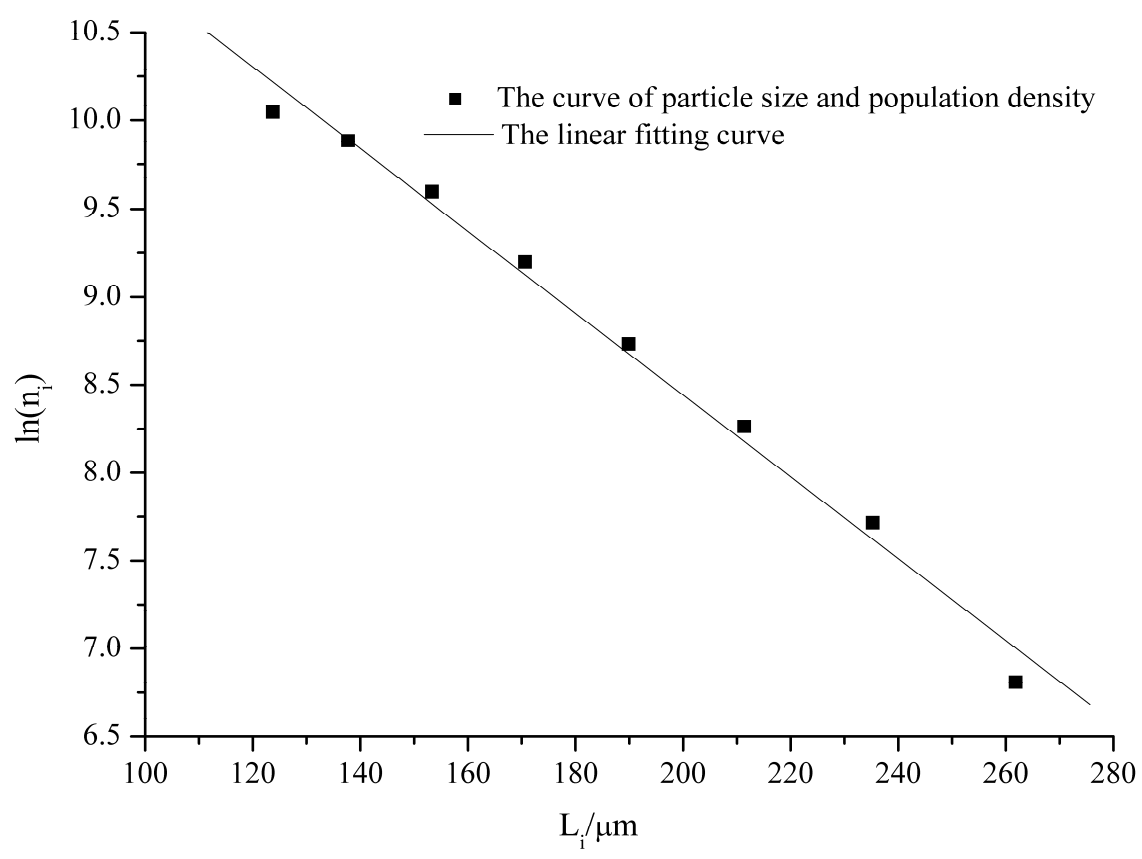

Fig. 2 - Typical experimental population density plot of rubidium chloride. 


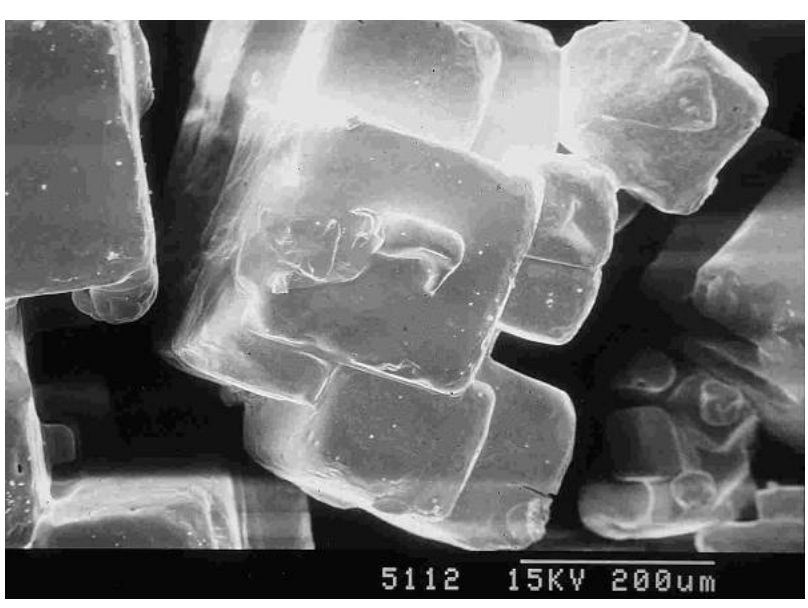

Fig. 3 - SEM of $\mathrm{RbCl}$ crystal from the kinetic experiment.

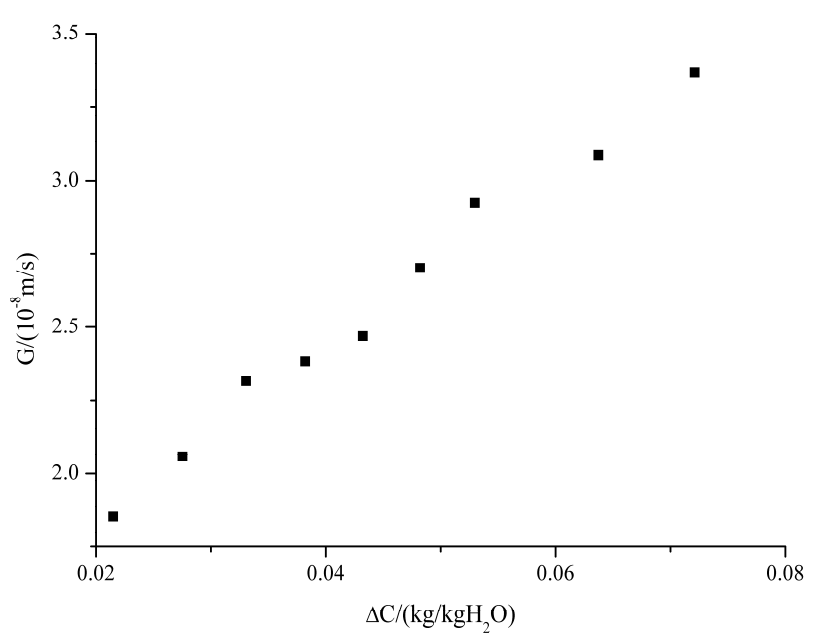

Fig. 5 - Effect of supersaturation of solution on growth rate of crystal.

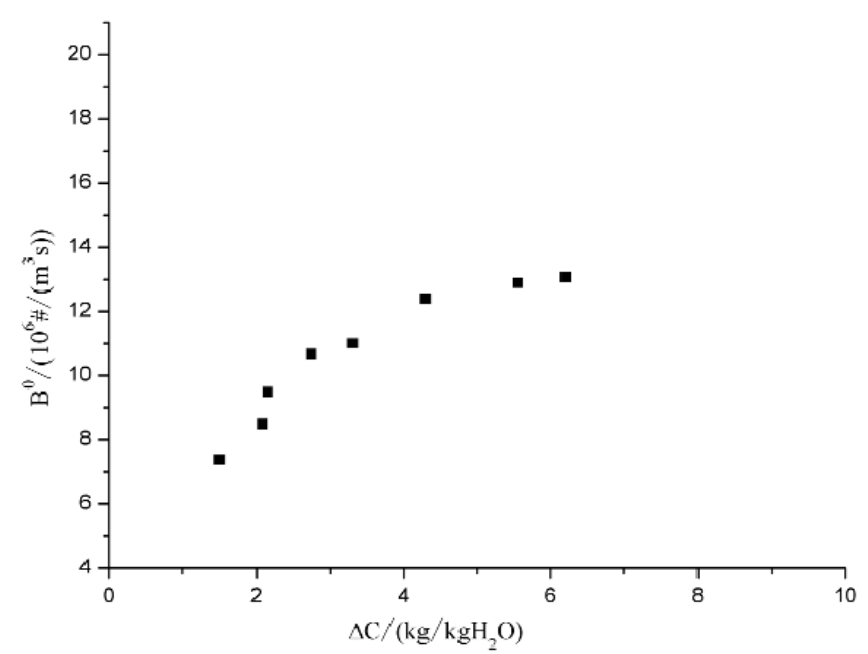

Fig. 7 - Effect of supersaturation of solution on rate of crystal on rate of $\mathrm{RbCl}$ nucleation.

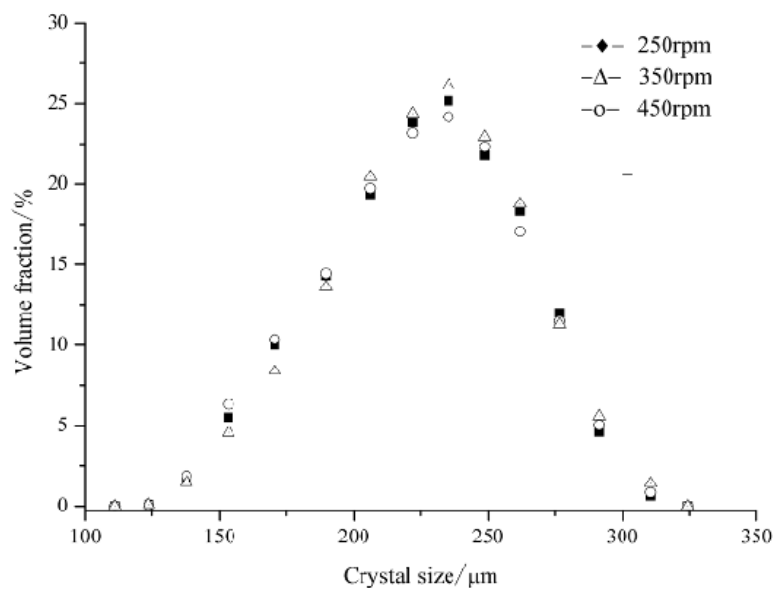

Fig. 4 - Crystal size distribution at different stirring rate.

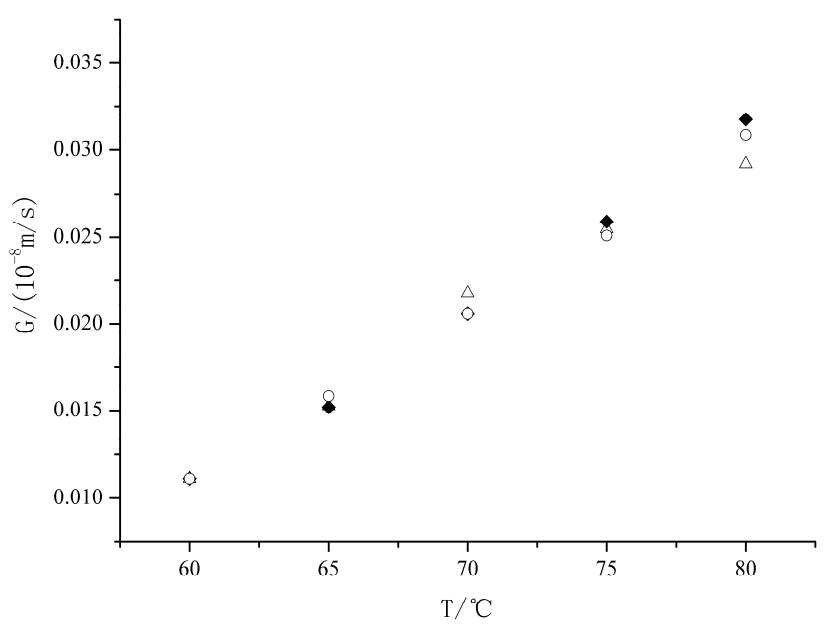

Fig. 6 - Effect of temperature on growth rate of crystal - $\Delta-$ : $250 \mathrm{rpm},-0-: 350 \mathrm{rpm}, \quad-\quad$-: $450 \mathrm{rpm}$.

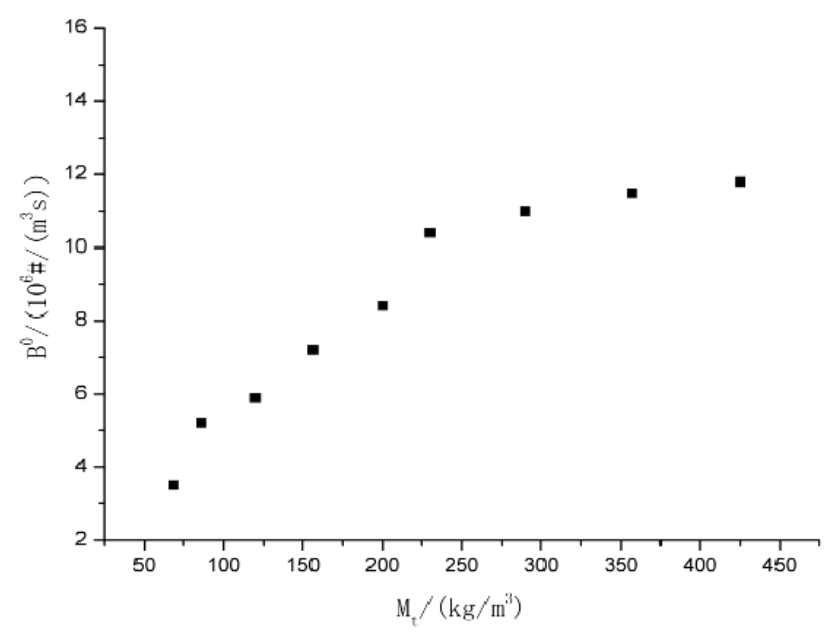

Fig. 8 - Effect of magma density of $\mathrm{RbCl}$ nucleation. 


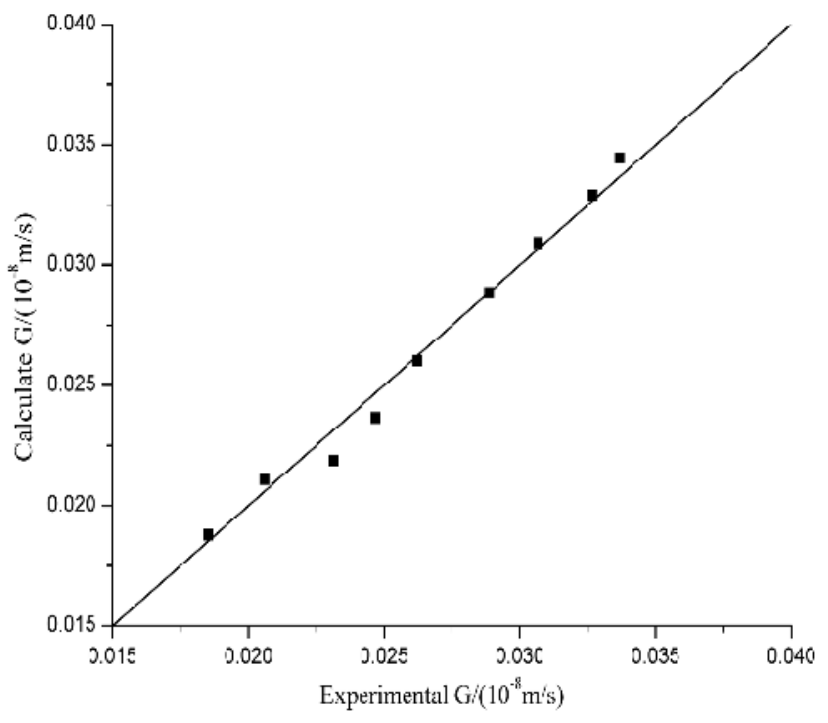

Fig. 9 - Comparison of experimental growth rates of crystal.

\section{The Regression Results of Kinetic Models}

According to the magma density, supersaturation, and crystal size distribution acquired from crystal slurry at differen residence times, and $\ln \left(\mathrm{n}_{\mathrm{i}}\right)$ is linearly related to $\mathrm{L}_{\mathrm{i}}$, the slope and linear intercept of the line represents, respectively, $-1 / \mathrm{G \tau}$, and $\mathrm{n}^{0}$. Then nucleation rate can be obtained under different conditions by the equation $\mathrm{B}^{0}=\mathrm{Gn}^{0}$. At the same time, different nucleation rate and growth rate will be obtained within the same time interval. Eventually, those parameters of kinetic model were calculated out by using the least square method. ${ }^{20}$ Based on the models in eq (3), and (4), the following correlations were obtained

$$
\begin{gathered}
G=2.2826 \times 10^{-6} \exp \left(-\frac{9.7232}{R T}\right) \Delta C^{0.3828} \\
B^{0}=4.6297 \times 10^{5} n_{p}^{0.8325} G^{1.0756} M_{t}^{1.1722}
\end{gathered}
$$

The activation energy of the crystal growth process is $9.7232 \times 103 \mathrm{~J} / \mathrm{mol}$ shown in equation (5). The exponential of magma density is 1.1722 shown in equation (6), indicating that the crystal nucleation rate will rise significantly with increasing of magma density. And with the increasing of supersaturation, the increasing of nucleation rate is more obviously than the growth rate, even if both increase. Therefore, the rubidium chloride crystal size can be controled by

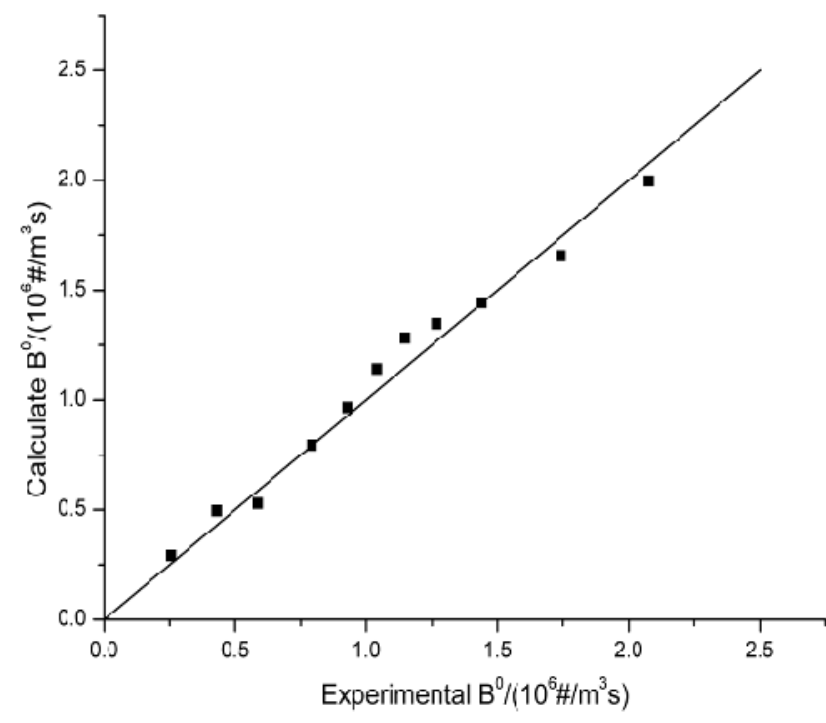

Fig. 10 - Comparison of experimental nucleation rates with values calculated by kinetic model of crystal with values calculated by kinetic model.

controlling the degree of supersaturation. In addition, the crystallization prcess of rubidium chloride is controled by surface reaction, because of the exponential of supersaturation is 0.3828 shown in equation (5).

Nucleation rate and growth rate calculated by equation (5), and (6), and obtained by experiment are shown in Figures 9, 10. The mean deviation of growth rate was $1.27 \%$ and the mean deviation of nucleation rate is $2.02 \%$.

\section{CONCLUSION}

Evaporation crystallization of rubidium chloride was performed in a MSMPR crystallizer from aqueous solution. Several conclusions can be drawn from the results of this study.

According to a tapcial crystal size distribution figure, the crystal growth of rubidium chloride evaporation crystallizatin has nothing to do with the initial crystal size. The rubidium chloride nucleation rate equation and growth rate equation were calculated out from semiempirical equations.

The crystals growth benefits from the increasing of supersaturation and temperature, and magma density has a great influence on the crystals nucleation, judging fron the exponential values as shown in the power law kinetics model. The experimental results fit to theoretical calculations are good. 


\section{Nomenclature}

rpm - stirrer speed, rev $\min ^{-1}$

$n \quad$ - population density, $\mathrm{m}^{-4}$

$t \quad$ - time, $\mathrm{s}$

$G \quad-$ growth rate, $\mu \mathrm{m} \mathrm{s}^{-1}$

$Q \quad$ - volumetric feed flow rate, $\mathrm{mL} \mathrm{s}^{-1}$

$Q_{i} \quad$ - volumetric discharge rate, $\mathrm{mL} \mathrm{s}^{-1}$

$B \quad$ - nuclei birth rate, $\mathrm{m}^{-4} \mathrm{~s}^{-1}$

$D \quad$ - nuclei death rate, $\mathrm{m}^{-4} \mathrm{~s}^{-1}$

V $\quad$ - slurry volume, $\mathrm{mL}$

\section{REFERENCES}

1. G. Kirchhoff and R. Bunsen, Ann. Phys. Berlin., 1860, 186, 161-189.

2. F. S. Wagner, "Rubidium and Rubidium Compounds", Kirk-Othmer Ency. Chem. Tech, forth edition, Wiley and Sons, New York, 1997.

3. Z. Lü, Z. Deng, H. Du, et al. Solid-State Ele., 2009, 53, 1154-1158.

4. W. C. Butterman and R. G. Reese, "Mineral Commodity Profiles Rubidium”, US Geological Survey, 2003.

5. J. Zhong, W. Yao and W. Lee, Int. J. Dev. Neurosci., 2007, 25, 359-365.

6. H. E. Sartori, Pharmacol. Biochem. Be., 1984, 21, 11-13.

7. I. Yasunori, K. Wataru, O. Osamu and M. Takaji, Top. Catal., 2010, 53, 019-1024.

8. S. Shi, J. L. Sun, G. S. Zhang, et al. Physica. B, 2005, 362, 266-270.

9. Q. Yin, Y. Zeng, X. Yu, et al. J. Chem. Eng. Data., 2013, $58,2875-2880$.
$L-$ characteristic crystal dimension, $\mu \mathrm{m}$

$B^{0} \quad-$ nucleation rate, $\mathrm{m}^{-3} \mathrm{~s}^{-1}$

$K_{n} \quad-$ nucleation rate constant

$K_{g} \quad-$ growth rate constant

$M_{t} \quad-$ crystals suspension density, $\mathrm{kg} \quad \tilde{\mathrm{m}}^{3}$

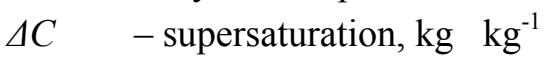

$E_{g} \quad$ - activation energy of growth rate, $\mathrm{J}^{\mathrm{mol}^{-1}}$

$\mathrm{g} \cdot \mathrm{i} \cdot \mathrm{j} \cdot \mathrm{h} \quad$ - experience kinetic parameters

$\tau \quad-$ crystal residence tim, $\mathrm{s}$

10. L. Sowul and M. A. F. Epstein, Ind. Eng. Chem. Proc. Des. Dev., 1981, 20, 197-203.

11. J. S. Wey, Chem. Eng. Commu., 1985, 35, 231-252.

12. S. H. Chung, D. L. Ma and R. D. Braatz, Chemometr. Intell. Lab., 2000, 50, 83-90.

13. A. D. Randolph and M. A. Larson, "Theory of Particulate Process", Academic Press, New York, 1971.

14. A. Y. Sheikh and A. G. Jones, AIChE J., 1998, 44, 16371645.

15. A. S. Myerson "Handbook of Industrial Crystallization", Butterworth Heinemann, Boston, 2002, p. 58-60.

16. J. Estrin, "Preparation and Properties of Solid State Materials", Marcel Dekker, New York, 1976, p. 1-20.

17. E. Kougoulos, A. G. Jones and M. W. Wood-Kaczmar, J. Cryst. Growth., 2005, 273, 520-528.

18. M. A. Larson and J. Garside, Chem. Eng. London., 1973, 274, 318-328.

19. J. L. Quon, H. Zhang, A. Alvarez, et al. Cryst. Growth Des., 2012, 12, 3036-3044.

20. F. Puel, G. Fevotte and J. P. Klein, Chem. Eng. Sci., 2003, 58, 3729-3740. 